Discussion Paper No. 08-127

ICT, Consulting and Innovative Capabilities

Daniel Cerquera

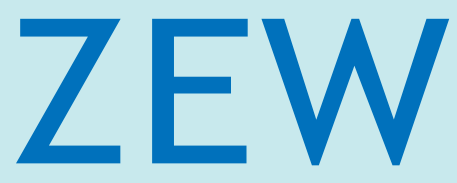

Zentrum für Europäische Wirtschaftsforschung $\mathrm{GmbH}$

Centre for European

Economic Research 
Discussion Paper No. 08-127

\title{
ICT, Consulting and Innovative Capabilities
}

\author{
Daniel Cerquera
}

Download this ZEW Discussion Paper from our ftp server:

$\mathrm{ftp}: / / \mathrm{ftp} . z e w . d e / p u b / z e w-d o c s / d p / d p 08127 . p d f$

Die Discussion Papers dienen einer möglichst schnellen Verbreitung von neueren Forschungsarbeiten des ZEW. Die Beiträge liegen in alleiniger Verantwortung der Autoren und stellen nicht notwendigerweise die Meinung des ZEW dar.

Discussion Papers are intended to make results of ZEW research promptly available to other economists in order to encourage discussion and suggestions for revisions. The authors are solely responsible for the contents which do not necessarily represent the opinion of the ZEW. 


\section{Non-technical summary}

Over the last decade, industrialized economies have experienced a dramatic increase in their expenditures on information and communication technologies (ICT) and there is broad evidence indicating that the adoption of ICT has contributed significantly to their productivity growth. The main argument behind the positive impact of ICT on productivity states that the use of ICT allows firms to redesign their production processes and to introduce new products and services. At the same time, due to the increasing complexity of ICT solutions, the capabilities at the firm level to successfully implement state-of-the-art ICT applications might be insufficient. As a consequence, it is not surprising that the demand for ICT consulting services has also evidenced a steady growth in the last years.

This paper analyzes the impact of ICT consulting on firms' performance. The analysis is divided in two main parts. First, the paper develops a theoretical model that explains the effect of the decision to contract ICT consulting on firms' performance and, more specifically, on firms' innovation incentives considering a pool of heterogeneous firms. Second, using a firm-level representative sample of the German manufacturing and service sectors, the paper empirically analyzes some implications of the theoretical model.

The analysis provides three main results. First, the results of the theoretical model show that ICT consulting increases aggregate incentives to innovate. This result is not corroborated by the empirical application. In particular, ICT consulting does not exhibit any impact on the probability of introducing product or process innovations nor on the number of such innovations. Interestingly, the results show that ICT consulting actually affects negatively the value of the introduced product and processes innovation. Second, the theoretical model suggests that low productivity firms might evidence either lower, unaffected or higher incentives to innovate. The empirical application shows that low productivity firms exhibit higher incentives to innovate. Third, although the theoretical analysis shows that the lower the productivity level the more the incentives to contract ICT consulting, the empirical evidence is inconclusive on this matter. These results suggest that firms optimize their innovations portfolio through ICT consulting. 


\section{Das Wichtigste in Kürze}

Die Einführung von Informations- und Kommunikationstechnologien (IKT) hat innerhalb der letzten zwanzig Jahre zu Produktivitätssteigerungen in den Industriestaaten geführt. Auf Unternehmensebene ermöglichen IKT, Geschäftsprozesse neu zu organisieren sowie neue Produkte und Dienstleistungen einzuführen. Allerdings verursachen IKT-basierte Strategien auch Kosten aufgrund der zunehmenden Komplexität solcher Prozesse. Deshalb ist es kaum verwunderlich, dass die Nachfrage nach IKT-bezogenen Beratungsdienstleistungen innerhalb der letzten Jahre stetig zugenommen hat.

Diese Studie untersucht den Einfluss von IKT-Beratungen auf den Unternehmenserfolg. Die Studie ist in zwei Teile gegliedert. Im ersten Teil wird ein theoretisches Modell entwickelt, das den Effekt von IKT-Beratungen auf die Innovationsfähigkeit von heterogenen Unternehmen untersucht. Im zweiten Teil werden einige Ergebnisse des theoretischen Modells einer empirischen Analyse unterzogen.

Die empirischen Ergebnisse zeigen, dass IKT-bezogene Beratungsdienstleistungen den Wert von eingeführten Produkt- und Prozessinnovationen negativ beeinflussen. Darüber hinaus weisen Unternehmen, die weniger produktiv sind, höhere Innovationsanreize auf. Die theoretisch abgeleitete Hypothese, dass die Wahrscheinlichkeit IKT-bezogene Beratung in Anspruch zu nehmen umso größer ist, je geringer das Produktivitätsniveau eines Unternehmens, lässt sich empirisch nicht belegen. Diese Ergebnisse deuten darauf hin, dass Unternehmen ihr Innovationsportfolio durch IKT-Beratung optimieren. 


\title{
ICT, Consulting and Innovative Capabilities
}

\author{
Daniel CERQUERA* \\ ZEW Mannheim \\ Germany
}

December 30, 2008

\begin{abstract}
This paper analyzes the impact of the decision to contract ICT consulting on firms' innovative incentives. The paper develops a theoretical model and estimates some of its implications for a sample of German firms. In particular, the paper estimates the average treatment effect of the decision to contract ICT consulting on firms' innovative incentives, considering the role of endogeneity and unobserved heterogeneity in the correlated random coefficient model. The paper shows three main results. First, the theoretical model shows that ICT consulting increases aggregate incentives to innovate. This result is not corroborated by the empirical application. ICT consulting does not affect neither the probability of introducing product or process innovations nor the number of such innovations. The empirical results show that ICT consulting affects negatively the value of the introduced product and processes innovation. Second, the theoretical model suggests that low productivity firms might evidence either lower, unaffected or higher incentives to innovate. The empirical application shows that low productivity firms exhibit higher incentives to innovate. Third, although the theoretical analysis shows that the lower the productivity level the more the incentives to contract ICT consulting, the empirical evidence is inconclusive on this matter. These results suggest that firms optimize their innovations portfolio through ICT consulting.
\end{abstract}

Keywords: ICT Consulting, Competition and Innovation.

JEL Classification: D21, L13, O32.

\footnotetext{
*cerquera@zew.de. Centre for European Economic Research (ZEW), Mannheim, Germany. Research Group Information and Communication Technologies. I would like to thank Irene Bertschek and Gordon Klein for helpful comments and suggestions, as well as seminar participants at the ZEW 2007 Workshop on "Innovative Capabilities and the Role of Consultants in the Information Economy" in Mannheim, Germany, and at the 2008 Annual Meeting of the European Association for Research in Industrial Economics (EARIE) in Toulouse, France. Generous financial support from Volkswagen Stiftung made this research possible. All errors are mine.
} 


\section{Introduction}

Over the last decade, industrialized economies have experienced a dramatic increase in their expenditures on information and communication technologies (ICT) and there is broad evidence indicating that the adoption of ICT has contributed significantly to their productivity growth 11 The main argument behind the positive impact of ICT on productivity states that the use of ICT allows firms to redesign their production processes and to introduce new products and services.2 At the same time, due to the increasing complexity of ICT solutions, the capabilities at the firm level to successfully implement state-of-the-art ICT applications might be insufficient to exploit their full potential. As a consequence, it is not surprising that the demand for ICT consulting services has also evidenced a steady growth in the last years. For instance, in 2007, nearly 22 percent of the 16.4 billion euros German consulting market was ICT related ${ }^{3}$

This paper analyzes the impact of ICT consulting on firms' performance. In spite of the relevance and apparent recent economic importance of ICT consulting, this paper represents a first attempt to quantify its economic benefits. The analysis is divided in two main parts. First, the paper develops a theoretical model that explains the effect of the decision to contract ICT consulting on firms' performance and, more specifically, on firms' innovation incentives. Second, using a firm-level representative sample of the German manufacturing and service sectors, the paper empirically analyzes some implications of the theoretical model. Particular focus is placed on whether ICT consulting affects the innovative capabilities of the analyzed firms, based on the insights provided by the theoretical model.

The paper is related with several strands of literature. First, on the theoretical side, the decision to contract ICT consulting is similar to the literature on outsourcing and vertical integration. In this literature, a (downstream) firm must decide whether to acquire a given input through the market (e.g. from an upstream firm) or to produce it internally (e.g. integrate with the upstream firm) $!^{5}$ In particular, Brocas (2003), Banerjee and Lin (2003) and Buehler and Schmutzler (2008) consider the firms' innovation incentives in a downstream-upstream framework in which the downstream firms must decide whether to vertically integrate or not with

\footnotetext{
${ }^{1}$ See OECD (2003), Draca et al. (2007) and Jorgenson et al. (2008).

${ }^{2}$ Bresnahan and Trajtenberg (1995) coined the notion of ICT as an enabling technology that is an important, but not sufficient prerequisite for technological progress in the overall economy. See also Brynjolfsson and Hitt (2000).

${ }^{3}$ See BDU (2008).

${ }^{4}$ More generally, the literature on the boundaries of the firm inspired by Hart and Moore (1990) is also related with the present paper. However, that literature has been focused on the determinants of vertical integration and the role of asset ownership, as opposed to the process of production and diffusion of innovations. See Hart (1995) for an introduction to this literature from the property rights point of view.

${ }^{5}$ If the input is the knowledge of how to assess and implement a new ICT infrastructure, the decision to contract ICT consulting is equivalent to acquire the input in the market, whereas leaving the task to the firm's ICT department is equivalent to internally produce it.
} 
their upstream input providers. Brocas (2003) specifically analyzes the innovation incentives of the upstream firms that invest in $R \& D$ and the subsequent process of licensing of the resulting innovations. In particular, Brocas (2003) studies the impact of vertical integration on the licensing and R\&D investment decisions.

Banerjee and Lin (2003) also consider a downstream-upstream setup in which, as opposed to Brocas (2003), the downstream firms invests in R\&D. In that paper, the authors consider the role of different input price contracts offered by the upstream firms and the role of vertical integration between them and the downstream firms. Buehler and Schmutzler (2008) present a similar analysis to the one presented in Banerjee and Lin (2003) but embed the analysis into a successive oligopoly framework. The authors do not consider the form of the input pricing contracts. Instead, they analyze the role of competition in the upstream market for the R\&D incentives of the downstream firms and the impact of the eventual vertical integration decisions. Although the modeling strategy is similar, the theoretical framework proposed here does not explicitly consider the structure of the upstream market. Instead, this paper focuses on the interaction between firm asymmetries and the potential benefits of the ICT consulting decision. Second, and in comparison with the existing empirical work, this paper is also related with the voluminous literature on the productivity impact of ICT. Draca et al. (2007) provide a comprehensive survey on the relationship between ICT and productivity, and conclude that the empirical evidence strongly suggests that ICT have had a positive and robust impact on firms' productivity. Although the present paper highlights some preliminary results on the positive impact that ICT and ICT consulting might have on firms' observed productivity, the empirical analysis presented here is focused on the impact of ICT consulting on firms' innovative capabilities.

The current analysis departs from most of the literature reviewed by Draca et al. (2007) by considering the role of an oligopolistic setup based on the literature previously described. As will be discussed below, an oligopolistic setup is motivated by the observation that $75 \%$ of the sampled firms reported facing less than twenty competitors, while $50 \%$ reported less than seven. By deviating from the traditional neoclassical approach, the present paper is able to consider the role of intra-industry competitive pressure faced by firms, and the role of ICT as a source of competitive advantage, as highlighted by some recent literature.

Therefore, and third, this paper is also related with the literature on the impact that the adoption of ICT might have on industry evolution. Given the role of ICT as enabling technologies, there is a growing body of literature showing that their implementation is a complex, dynamic task. This process tends to be gradual, starting with a negligible restructuring of inputs of production and followed over time by continuous reorganization and expansions at the firm level. As some firms in this process reap the benefits of ICT sooner (and better) than others, ICT 
represent a source of firm heterogeneity that might generate important competitive advantages. Theoretically, Helpman (1998) summarizes the seminal treatments of the impact of ICT as general purpose technologies (GPT), on the technological progress of the overall economy ${ }^{6}$

Empirically, Chun et al. (2007) estimate the positive impact of ICT use on firm heterogeneity for a panel of U.S. firms from 1971 to 2000. They find evidence of creative destruction (i.e. increased competition) at the firm level due to the implementation of ICT. That is, through their use of ICT, more productive firms displace less productive firms. Cerquera and Klein (2008) empirically demonstrates that ICT has a robust impact on firm heterogeneity only when ICT is used intensively and jointly with specific ICT applications. Moreover, ICT induced heterogeneity is shown to have a positive impact on the decision to invest in R\&D personnel. Theoretically, this paper captures this competitive effect by means of an oligopolistic setup. The present analysis considers the role of firm asymmetries (i.e. heterogeneity) in the form of marginal cost differences and develops, theoretically and empirically, their interaction with the decision to contract ICT consulting.

More specifically, this paper proposes a model of oligopolistic competition and explicitly considers the decision to contract ICT consulting and the incentives to invest in cost-reducing R\&D. More specifically, the model describes an industry that evolves through three stages. In the first stage, the ICT consulting decision is taken, considering the potential benefits attached to the role of the consultant. The second stage describes the investment in R\&D in order to reduce operation costs. Finally, in the third stage, firms compete in the product market given the realized benefits from the ICT consulting decision and the R\&D investments.

In addition, the empirical implications of the model, in terms of the impact on innovation incentives of the ICT consulting decisions, are derived and estimated using a representative firm-level sample of the German manufacturing and service sectors. The analysis provides three main results. First, the results of the theoretical model show that ICT consulting increases aggregate incentives to innovate. This result is not corroborated by the empirical application. In particular, ICT consulting does not exhibit any impact on the probability of introducing product or process innovations nor on the number of such innovations. Interestingly, the results show that ICT consulting actually affects negatively the value of the introduced product and processes innovation.

Second, the theoretical model suggests that low productivity firms might evidence either lower, unaffected or higher incentives to innovate. The empirical application shows that low productivity firms exhibit higher incentives to innovate. Third, although the theoretical analysis shows that the lower the productivity level the more the incentives to contract ICT consulting,

${ }^{6}$ See also Jovanovic and Rousseau (2005). 
the empirical evidence is inconclusive on this matter. These results suggest that firms optimize their innovations portfolio through ICT consulting.

The paper is organized as follows. The second section presents a theoretical model that considers the decision to contract ICT consulting in an oligopolistic setup in the presence of R\&D investments. After the model is analyzed, the main empirical implications with respect to the innovative behavior are derived. The third section presents a description of the data and the empirical analysis of the empirical implications derived from the theoretical framework. The fourth section concludes.

\section{The Model}

In this section, the paper develops a theoretical model that considers the decision to contract ICT consulting, as well as the decision to invest in R\&D investments. In particular, the model corresponds to a duopoly game in order to account for the strategic motives to contract ICT consulting and to invest in cost-reducing innovations. The model describes an industry that evolves through three stages. In the first stage, the ICT consulting decision is taken, considering the potential benefits attached to the role of the consultant. The second stage describes the investment in R\&D in order to reduce operation costs. Finally, in the third stage, firms compete in the product market given the realized benefits from the ICT consulting decision and the R\&D investments.

\subsection{Setup}

The model considers a simplified duopoly industry that competes in Cournot quantities, although a generalization to an $n$ number of firms is straightforward. In particular, it is assumed that firms compete under (initially given) asymmetric cost structures in order to investigate the impact of the ICT consulting decision across a pool of heterogeneous firms. This asymmetry is modeled in a way that allows to exactly identify its impact and to make it comparable with a symmetric standard case.

Initially, it is also assumed that only one firm decides on whether to contract ICT consulting or not. This assumption allows the analysis of the impact on the strategic motives of the industry under study and significantly reduces the number of cases to be considered. The industry faces a linear inverse demand curve of the form $P(Q)=a-Q$, with $Q=q_{1}+q_{2}$ and $a>0$, while its firms exhibit marginal costs of the form 7

\footnotetext{
${ }^{7}$ The papers by Brocas (2003), Banerjee and Lin (2003) and Buehler and Schmutzler (2008) also consider linear
} 


$$
\begin{gathered}
c_{1}=c+\delta-I-y_{1} \\
c_{2}=c-\delta-y_{2} .
\end{gathered}
$$

In this specification, $c$ corresponds to an initially given (symmetric) marginal costs, $\delta$ represents the source of the imposed asymmetry between the two firms and $I$ summarizes the impact of the consulting decision. Note that firm 1 is assumed to be a less productive firm (i.e. marginal costs are higher by $\delta$ ) in comparison with its competitor, firm 2 . This specification also implies that the benefits of the ICT consulting are assumed to take the form of a reduction in marginal $\operatorname{costs} 8$ Finally, $y_{1}$ and $y_{2}$ represent the reduction of costs due to the firms' own R\&D investments. Note that for simplicity $y_{1}$ and $y_{2}$ are not multiplied by any coefficient measuring the extent of their impact 9

In the first stage, firm 1 has to decide whether to contract ICT consulting or not. That is, $I$ is represented by,

$$
I= \begin{cases}\theta w & \text { If firm } 1 \text { contracts ICT consulting } \\ 0 & \text { Otherwise }\end{cases}
$$

In this specification, $w$ constitutes the impact on marginal costs associated with the ICT consulting decision, while $\theta$ is a parameter that measures the extent of such impact. For simplicity, it is assumed that this decision implies an investment in the form of a fixed cost of operation given by $f: 10$ Therefore, given initial marginal costs and R\&D investments, firm 1 evaluates whether the incremental benefit in profits (if any) from ICT consulting is greater than its introduction cost $f$.

In the second stage, both firms invest in $R \& D$ in order to improve their marginal costs of operation. It is assumed that the translation from $R \& D$ investments into actual process innovations is deterministic and one-to-one, although a stochastic extension is straightforward.

demand functions in duopoly Cournot models. These demand functions can be derived from a quadratic utility function. See Singh and Vives (1984).

${ }^{8}$ Due to the role of ICT as an enabling technology, the present approach considers ICT consulting as a step in reducing marginal costs through the introduction of new methods to improve the firm's internal operational processes. This implicitly suggests that the firm, may be due to lack of knowledge, is not capable to introduce such improvements by itself.

${ }^{9}$ This assumption greatly simplifies the calculations, although the consideration of such coefficients is straightforward. See Milstein and Tishler (2008). A more general specification is the objective of ongoing research.

${ }^{10}$ It is possible to consider the cost of the consulting decision as affecting the marginal cost of operation. For example, this could be the case when the consulting activity requires constant monitoring by the contracting firm. However, for the purpose of the present paper, the adopted specifications suffices. 
This implies that $R \& D$ incentives are equal to the reduction in marginal costs. It is further assumed that these investments exhibit a cost equal to $k y_{i}^{2}$ for $i=1,2$, where $k$ is a cost parameter 11

Finally, in the third stage, and once the outcome of the ICT consulting and the R\&D investments is realized, firms compete in Cournot fashion in the product market. Since the approach looks for the subgame-perfect Nash equilibrium, the analysis of the model begins with the last stage of the game.

\subsection{Stage 3: Product Market Competition}

In this stage, marginal costs are taken as given. These costs are dependent on the level of the initial asymmetries, investments in R\&D and consulting decisions that are defined in the first two stages. Therefore, for $i=1,2$ and $i \neq j$, firms choose quantities in order to maximize the following profits:

$$
\Pi_{i}\left(c_{i}, c_{j}\right)=q_{i} \cdot\left(P(Q)-c_{i}\right)
$$

The case where firm 1 decides to contract ICT consulting is considered first and, as mentioned above, firm 1 is a less productive firm 12 Therefore, under this specification, marginal costs are given by:

$$
\begin{gathered}
c_{1}=c+\delta-\theta w-y_{1} \\
c_{2}=c-\delta-y_{2} .
\end{gathered}
$$

Assumption 1. $\theta w \geq 0$.

Assumption 1 implies that ICT consulting is always successful. That is, once it is contracted, ICT consulting unambiguously provides a reduction in marginal costs. This assumption reduces the number of cases to be considered and it is in line with some empirical evidence ${ }^{13}$

After solving the profit maximization problem, equilibrium Cournot quantities are given by

\footnotetext{
${ }^{11}$ There is little empirical evidence on the functional form of the cost structure of R\&D programs. The adopted specification is motivated by its convenience and predominance in existing theoretical literature.

${ }^{12}$ Note that the subgame when firm 1 decides not to contract ICT consulting is equivalent to a symmetric Cournot game.

${ }^{13}$ In the data used for the empirical applications (and described in the next section) the majority of respondents indicated that the contracted ICT consulting was successful.
} 
$q_{i}^{*}=q_{i}^{*}\left(y_{1}, y_{2} ; c, \delta, w, \theta\right)$ for $i=1,2$. More specifically,

$$
\begin{aligned}
q_{1}^{*}\left(y_{1}, y_{2}\right) & =\frac{a-c-y_{1}+2 y_{2}}{3}+\frac{2 \theta w}{3}-\delta \\
& =\bar{q}_{1}^{*}\left(y_{1}, y_{2}\right)+\frac{2 \theta w}{3}-\delta \\
q_{2}^{*}\left(y_{1}, y_{2}\right) & =\frac{a-c-y_{2}+2 y_{1}}{3}-\frac{\theta w}{3}+\delta \\
& =\bar{q}_{2}^{*}\left(y_{1}, y_{2}\right)-\frac{\theta w}{3}+\delta .
\end{aligned}
$$

In this expression, $\bar{q}_{1}^{*}\left(y_{1}, y_{2}\right)$ and $\bar{q}_{2}^{*}\left(y_{1}, y_{2}\right)$ correspond to the optimal quantities in the twostage R\&D Cournot game for the cases where there are no cost asymmetries. This allows the analysis to exactly identify the role of firms' heterogeneity and the consulting decision.

Assumption 2. Given investment levels $\left(y_{1}, y_{2}\right)$, both firms produce, in equilibrium, positive quantities.

Assumption 2 requires that the equilibrium price is higher than the maximum (equilibrium) marginal cost between the two firms and, in consequence, imposes also restrictions on the optimal investment levels to be derived in the next stage ${ }^{14}$ These conditions can be achieved if $a$ and $a-c$ are large enough. Although this assumption can be easily relaxed, it is maintained in order to develop testable hypotheses, while considering a small number of cases. In the next subsection, the result of the investment stage is presented.

\subsection{Stage 2: $\mathrm{R} \& D$ Investments}

The previous subsection presented the outcome of the product market competition, taking as given the incentives to innovate. In this subsection the $R \& D$ investment levels that, from the firms' perspective maximize their profits, are calculated. In consequence, for $i=1,2$ and $i \neq j$, firms maximize profits of the form:

$$
\Pi_{i}\left(y_{i}, y_{j}\right)=q_{i}^{*}\left(y_{i}, y_{j}\right) \cdot\left(P\left(Q^{*}\left(y_{i}, y_{j}\right)\right)-c_{i}\left(y_{i}\right)\right)-k y_{i}^{2}
$$

For simplicity, the cost parameter $k$ is set equal to one. It is possible to consider $k$ as a free

\footnotetext{
${ }^{14}$ See Assumption 3 .
} 
parameter but, as long as $k$ is not too low, the results do not change. ${ }^{15}$

After calculating the first order conditions, and checking second order conditions, equilibrium investments are given by:

$$
\begin{aligned}
y_{1}^{*} & =\frac{2(a-c)}{7}+\frac{8 \theta w}{7}-2 \delta \\
& =\bar{y}^{*}+\frac{8 \theta w}{7}-2 \delta \\
y_{2}^{*} & =\frac{2(a-c)}{7}-\frac{6 \theta w}{7}+2 \delta \\
& =\bar{y}^{*}-\frac{6 \theta w}{7}+2 \delta .
\end{aligned}
$$

As in the previous stage, $\bar{y}^{*}$ correspond to the symmetric R\&D investment that would be observed in the absence of any cost asymmetry. Note that in this case the introduction of ICT consulting provides an investment incentive for firm 1. This result follows from the deterministic nature of the assumed R\&D technology. In particular, any factor that affects profits positively will have a positive impact on innovation incentives ${ }^{16}$ Interestingly, the results of this stage show that the additional incentives provided by the contracting of ICT consulting can be reduced, and actually overcompensated, by the level of asymmetry initially assumed 17

Assumption 3. Both firms exhibit in equilibrium positive investments in RESD.

Jointly with the second order conditions, Assumption 3 implies that equilibrium investments are interior solutions. As with Assumption 2, this requires that $a$ and $a-c$ are large enough. In the next subsection, the consulting decision of firm 1 is considered.

\subsection{Stage 1: Consulting Decision}

Given the analysis of the product market competition and the innovation incentives, this stage determines the conditions under which firm 1 will find it optimal to contract ICT consulting.

\footnotetext{
${ }^{15}$ Setting $k=1$ guarantees that the conditions on the second order conditions for an optimal R\&D level are met.

${ }^{16}$ See Reinganum (1989).

${ }^{17}$ Although adopting a stochastic R\&D specification might enrich the results, the basic results tend to be maintained. See Milstein and Tishler (2008). A more general specification is the objective of ongoing research.
} 
In addition, an assessment of the impact of firm 1 decision on overall industry performance can be provided.

From the previous subsections, substituting equations (4), (5), (7) and (8) in equations (2), (3) and (1) the following expressions for firms' profit can be obtained:

$$
\begin{gathered}
\Pi_{1}^{*}=\frac{5(a-c-7 \delta+4 \theta w)^{2}}{49}-f \\
\Pi_{2}^{*}=\frac{5(a-c+7 \delta-3 \theta w)^{2}}{49} .
\end{gathered}
$$

Note that, gross of consulting costs, ICT consulting positively affects the profits of firm 1 more than it negatively impacts the profits of firm 2 . Let $\Delta \Pi_{i, j}^{c}$ define the difference between the two firms' profits, gross of consulting costs. Then, the contracting of ICT consulting by firm 1 increases overall industry profits if the following holds:

$$
\Delta \Pi_{i, j}^{c}=\bar{f} \geq f .
$$

In addition, it can also be shown that the difference in profits of firm 1 with and without consulting is given by:

$$
\Delta \Pi_{1}^{c}=\frac{40 w(a-c+7 \delta-2 \theta w)}{49} .
$$

Therefore, firm 1 will contract ICT consulting if and only if

$$
\Delta \Pi_{1}^{c} \geq f
$$

Moreover, equation (12) shows that the higher the initial cost asymmetry against firm 1, the higher the incentives to contract ICT Consulting. The next subsection presents a summary of the results in order to develop testable hypotheses.

\subsection{Equilibrium Characterization}

According to the results presented in the previous sections, the following equations completely characterize the Cournot equilibrium. That is: 


$$
\begin{aligned}
q_{1}^{*} & =\widetilde{q}^{*}+\frac{12 \theta w}{7}-3 \delta \\
q_{2}^{*} & =\widetilde{q}^{*}-\frac{9 \theta w}{7}+3 \delta \\
Q^{*} & =\widetilde{Q}^{*}+\frac{3 \theta w}{7} \\
C S^{*} & =\frac{\left(Q^{*}\right)^{2}}{2} .
\end{aligned}
$$

Where $\widetilde{q}^{*}$ and $\widetilde{Q}^{*}$ represent the symmetric Cournot equilibrium quantities and are equal to $\widetilde{q}^{*}=3(a-c) / 7$ and $\widetilde{Q}^{*}=6(a-c) / 7$, respectively. In addition, equations $(7)-10$ presented before correspond to the equilibrium $\mathrm{R} \& \mathrm{D}$ investments and profits of the two firms. Equation (17) is the equilibrium expression for consumer surplus.

In addition, the following result summarizes some interesting properties of the proposed model and represents the basis for the empirical strategy of the following section.

\section{Lemma 1. Properties}

i. Equilibrium investment incentives (i.e. value of innovations) are decreasing in the firm's own costs and increasing in firm's competitor's costs.

ii. Under Assumption 1 (i.e. successful ICT consulting) overall industry innovation level increases.

iii. For $f \leq \bar{f}$ and successful ICT consulting overall industry profits increase.

$i v$. Consumer surplus unambiguously increases in the presence of successful consulting.

Proof: Numeral i. can be obtained by taking the derivatives of equations (7) and (8) with respect to cost parameters $c, \delta$ and $\theta w$. Numeral ii. follows by adding equations (7) and (8), and comparing the cases $\theta w=0$ and $\theta w \geq 0$. Numeral iii. is derived in equation (11). Numeral iv. follows immediately from equations $(16)$ and $(17)$.

As mentioned above, the results presented so far can be translated into testable hypotheses. This is summarized in the next subsection. 


\subsection{Empirical Implications}

This subsection summarizes some empirical implications of the theoretical results presented before and translate them into testable hypotheses according to the available data. In addition, it discusses alternative strategies in order to evaluate the intuition for the results to motivate further empirical analysis. In particular, there are three main predictions of the model. These can be summarized as follows:

1. ICT consulting increases the incentives to innovate whenever its costs are low

2. Low productivity firms might evidence either lower, unaffected or higher incentives to innovate

3. The lower the productivity level the more the incentives to contract ICT consulting

The first hypothesis is in line with the literature on ICT adoption and highlights the potential of ICT to allow the introduction of more efficient production technologies. Along the lines of the theoretical model, note that ICT consulting increases industry profits whenever its costs are low (i.e. when equation (11) holds). Moreover, adding up the equilibrium R\&D investments of the two firms for the case of low costs of ICT consulting, it is clear that contracting ICT consulting increases aggregate incentives to innovate.

The second hypothesis highlights the cost dimension of the innovation processes. In particular, it is expected that low productivity firms (i.e. firm 1) reorganize and optimize their innovation portfolio. However, whether this implies less or more innovations is an empirical questions tackled in the next section. More specifically, note that for $\delta \leq \frac{3 \theta \omega}{7}$ it is always the case that $y_{1}^{*}>y_{2}^{*}$, while for $\delta \geq \frac{4 \theta \omega}{7}, y_{1}^{*}<y_{2}^{*}$ holds.

The third hypothesis motivates the decision to contract ICT consulting. As firms expect to benefit from the introduction of new ICT, low productivity firms might benefit more from such decision. This hypothesis is derived from taking the derivative of equation (12) with respect to $\delta$.

In addition, the impact that firms' size, economic sector and the intensity of ICT use might have on the results are considered. In particular, firms that depend more on ICT for their normal operations (i.e. ICT intensive firms) might evidence a stronger impact from the decision to contract ICT consulting. The next section presents the data and the specific empirical strategy of the paper. 


\section{Empirical Analysis}

This section presents the analysis of the impact of ICT consulting on firms' performance. The analysis is divided in two parts. First, the available data is described and some descriptive statistics are presented. Second, the analysis attempts to uncover the impact of ICT consulting on the innovative capabilities of the studied firms, taking into account the insights from the theoretical model developed above. In addition, the paper briefly discusses some preliminary additional results that support its main conclusions.

\subsection{Data}

The analysis is based on two waves of a business survey carried out by the Centre for European Economic Research (ZEW) corresponding to the years 2003 and 2006 (ZEW ICT Survey). The data set is a representative sample of the German manufacturing and service sector, and contains detailed information on the economic characteristics, performance and ICT use for 4,400 firms in each wave. Table 1 provides some descriptive statistics. In general, and in line with similar data sets at the firm level, the surveyed firms evidence a great variability with respect to sales (in millions euros), number of employees and labor productivity calculated as the ratio between sales and number of employees. In addition, the empirical distribution of the reported sales, as well as the number of employees appear to be left skewed. The median size of the surveyed firm corresponds to 50 employees, whereas the average is about 337.7 employees. This indicates the presence of few very large companies in the data.

Analogously, the median value of sales is 7 millions with an average of 131.7 millions. The same also holds for the distribution of labor productivity where the median and the mean are 0.13 and 0.24 millions per employee, respectively. This skewness present in the distributions of the reported data is consistent with empirical analyses at the firm level. Table 1 also includes information about the use and intensity of ICT. The intensity in the use of ICT is measured by the percentage of employees working mainly with a $\mathrm{PC}(\mathrm{PCW})$ and is nearly equally distributed around the different percentiles. In addition, the data also provides information about different ICT software applications, namely enterprise resource planning (ERP), supply chain management (SCM) and customer relationship management (CRM).

Table 2 shows how the use of these different ICT applications are related with different firm characteristics. These firm characteristics (e.g. sales and number of employees) vary if the firm uses ICT more intensively than the median (i.e. PCW greater than 50\%) or introduced ICT applications. Specifically, the table shows that the intense use of ICT, as well as the introduction of different ICT applications, is correlated with higher firm performance in terms of sales, number 
of employees and labor productivity. However, it should be noted that standard deviations are high through all the data, which indicates a high level of heterogeneity.

For example, the surveyed firms evidence 338 employees on average, whereas companies using ERP, SCM or CRM tend to be larger with 518, 518 and 627 average number of employees, respectively. The same can be observed in terms of sales. Firms using ICT applications or using ICT more intensively were more likely to exhibit higher sales. The average level of sales over all firms is 131.7 millions euros, whereas companies using CRM, SCM or ERP evidence 205.9, 222.8 and 209.2 millions, respectively. In general, these statistics show that firms using ICT more intensively tend to be larger than their counterparts.

Moreover, firms that use ICT more intensively and that introduce ICT applications do not only tend to be larger, but more efficient than other firms. In terms labor productivity (i.e. ration of sales and number of employees), it can be seen that the average is 0.24 million euros per employee. This is higher for firms using ICT more extensively. Specifically, companies using ICT more intensively (i.e. PCW greater than 50\%) exhibit a labor productivity of 0.31 millions euro per employee. Moreover, companies using CRM exhibit on average 0.27 millions euro per employee, while those using SCM and ERP evidence 0.26 millions and 0.27 millions per employee, respectively.

In addition to these general characteristics, the data also contains information regarding the innovation activities of the sampled firms. For instance, as a proxy for innovation incentives, the data contain information on the fraction of employees working on R\&D activities in 2006 (i.e. $\mathrm{R} \& \mathrm{D}$ intensity). The mean value of this variable is 0.17 with a median equal to 0.09 , indicating a left-skewed distribution.

Information on innovation outputs is also available. This includes dummy variables indicating whether the firm introduced product or process innovations during the periods 2001-2003 and 2004-2006, the number of such innovation introduced during 2004-2006, the percentage of sales reported in 2006 that are derived from the product innovations introduced during the period 2004-2006 (mean: 26.32, median: 20) and the percentage of cost reductions achieved in 2006 from the introduction of process innovations during the period 2004-2006 (mean: 9.49, median: 8).

The measure of ICT intensity, percentage of employees working with a PC (PCW), is positively correlated to all measures of innovation. This does not hold for the ICT applications considered. ERP use is related to a slightly higher amount of cost reductions with process innovations, while sales with product innovation slightly decreases from $27.4 \%$ to $25.8 \%$. The fraction of employees working on R\&D activities, however, is decreasing from $21.7 \%$ to $14.9 \%$. This is different for the case of CRM use. Sales with product innovations, cost reductions with 
process innovations and $R \& D$ intensity are positively related.

The previous descriptive evidence might suggest that size has an important impact on the decision to contract external ICT consulting. This could be the case because larger firms might be more able to afford the costs associated with such consulting. At the same time, firms that are more ICT intensive, rely more heavily on automated business processes and, therefore, require an updated ICT infrastructure. As a consequence, and given the role of ICT as an enabler of innovations, it is not surprising that firms that contracted ICT consulting are more productive.

However, the previous brief descriptive analysis does not take into account the impact of additional factors and does not allow the assessment of the potential (and causal) impact of ICT consulting on firms' overall performance. This is the objective of the next subsection, paying particular attention to the impact of ICT consulting on firms' innovative capabilities.

\subsection{Empirical Strategy}

The objective of the estimation of the average treatment effect (ATE) is to evaluate the impact of a given policy on a prespecified population for an outcome of interest. For the case considered in the present paper, the policy corresponds to the contracting of ICT consulting, the population is the German manufacturing and service sector, while the outcome of interest are the innovative capabilities of the German firms. The estimation of the ATE is equivalent to consider the difference in the innovative behavior between firms that contracted ICT consulting and the innovative behavior of those same firms, assuming, hypothetically, that they had not contracted ICT consulting.

As it has been clear in the literature, the problem with the estimation of ATE arises because for each firm only one potential case is observed: either it contracted ICT consulting or it did not. Therefore, the objective of the estimation of ATE is to build the counterfactual, unobserved case. Following Wooldridge (2008), this paper estimates the ATE considering three main specifications. First, the case of homogeneous treatment effect is considered. That is, it is assumed that all firms in the sample are affected equally by the contracting of ICT consulting and the objective is to recover the average impact. Second, the analysis considers the case of introducing unobserved firm heterogeneity. In this case, the assumption of equal impact of ICT consulting across firms is discharged. Under this specification, it is possible to identify the ATE, while simultaneously estimating the joint impact of ICT consulting on observable variables. Third, the case of correlated random coefficients is also considered. That is, the case where the ATE can be correlated with unobserved heterogeneity. Under this specification, the case of homogeneous and heterogeneous ATE can be considered. The following presentation 
summarizes the adopted approach.

Let $w_{i}$ be a dichotomous variable indicating whether firm $i$ contracted ICT consulting, in which case $w^{i}=1$, or not (i.e. $w^{i}=0$ ). $y_{0}^{i}$ corresponds in the present analysis to the innovative activity of firm $i$, given the contracting of ICT consulting, while $y_{0}^{i}$ is the innovative activity of firm $i$ without the contracting of ICT consulting and the ATE of interest is ATE $\equiv E\left[y_{1}-y_{0} \mid x\right]$, where $x$ are observable variables ${ }^{18}$ However, note that for each firm $i$ only one of the possible outcomes is observed. That is, depending on $w^{i}$, either $y_{0}^{i}$ or $y_{1}^{i}$ is observed.

Dropping firm indexes and assuming $w^{i}=w=1$ if ICT consulting is contracted (with $w^{i}=(1-w)=0$ if ICT consulting is not contracted), the observed outcome $y$ is equal to:

$$
y=(1-w) y_{0}+w y_{1}=y_{0}+w\left(y_{1}-y_{0}\right)
$$

As shown by Wooldridge (2002), it is useful to decompose the counterfactual outcomes into their means and stochastic parts. That is, $y_{0}=\mu_{0}+v_{0}$ and $y_{1}=\mu_{1}+v_{1}$, where, $E\left[v_{0}\right]=0$ and $E\left[v_{1}\right]=0$. The derivation of the three specifications mentioned above depends on the assumptions made on the stochastic components of the counterfactual outcomes. That is, under $E\left[v_{0} \mid x\right]=E\left[v_{1} \mid x\right]$ it can be shown that the ATE can be identified and corresponds to the homogeneous case. As expected, under $E\left[v_{0} \mid x\right] \neq E\left[v_{1} \mid x\right]$ and assumptions provided by Wooldridge (2002) the ATE can also be identified when unobserved heterogeneity is considered. Finally, the case of the ATE in the correlated random coefficients model considered in Wooldridge (2008) implies that the treatment variable $w$ interacts with unobserved heterogeneity, and the treatment variable $w$ and the unobserved heterogeneity are correlated. Moreover, following the conditions presented in Wooldridge $(2002,2008)$, the estimating equations can be derived and are equal to:

$$
\begin{aligned}
& y_{i, t}=\gamma+\alpha_{1} w_{i, t-1}+x \beta+e_{1} \\
& y_{i, t}=\gamma+\alpha_{2} w_{i, t-1}+x \beta+w(x-\bar{x})+e_{2} \\
& y_{i, t}=\gamma+\alpha_{3} w_{i, t-1}+x \beta+\rho h(x, z ; \widehat{\theta})+e_{3} \\
& y_{i, t}=\gamma+\alpha_{4} w_{i, t-1}+x \beta+w(x-\bar{x})+\rho h(x, z ; \widehat{\theta})+e_{4} .
\end{aligned}
$$

In the previous specifications, the parameter $\alpha_{j}$ (for $j=1,2,3,4$ ) corresponds to the ATE for each case and can be consistently estimated. More specifically, $\alpha_{1}$ corresponds to the homogeneous ATE, $\alpha_{2}$ is the ATE accounting for unobserved heterogeneity of treatment, and $\alpha_{3}$

\footnotetext{
${ }^{18}$ In order to account for observable variables $x$, additional assumptions must be met. In particular, ignorability of treatment given observed covariates $x$. See Wooldridge (2002) for details.
} 
and $\alpha_{4}$ identify the ATE under correlated random coefficients for the cases of homogeneous and heterogeneous treatments, respectively ${ }^{19}$ Moreover, under endogeneity of treatment, equations (19)-22 can be estimated by instrumental variables assuming $E\left[e_{j} \mid x, z\right]=0$ for $j=1,2,3,4$ given available instruments $z,{ }^{20}$

In this specifications from equations $(19)-(22), y_{i, t}$ represents the innovative output of firm $i$ at time $t$. Specifically, $t=2006$ given the data available. Although the database allows for the analysis of the impact of the ICT consulting decision on different innovative output variables, the analysis is initially performed considering the estimated reduction on overall costs for the year 2006 of all the process innovations introduced by the firm during the years 2004-2006. This variable is labeled as Value of Process Innovation 2006 and correspond to $y_{i, t}$ in equations (19)-22) ${ }^{21}$

$w_{i, t-1}$ corresponds to the binary $(0,1)$ decision to contract ICT consulting by firm $i$ at time $t-1$. In this case, $t-1=2003$ in order to reduce the potential endogeneity (to be discussed below) in this contracting decision. $x$ include firm specific and economic sector control variables that affect the operations of the firm and/or the decision to contract ICT consulting. In particular, $\bar{X}$ incorporates firm specific variables such as the intensity of ICT use or PCW (i.e. \% of employees that work mainly with a PC) , the type of ICT applications (i.e. ERP, SCM and CRM), the natural logarithm of the number of employees as a measure of size. All these variables correspond to the year 2003. On a more aggregated level, $\bar{X}$ also includes a service sector specific dummy variable and whether the firm was located in eastern or western Germany. In addition, a set of dummy variables that specifies whether firm $i$ belongs to a particular interval of the support of the labor productivity distribution for $t-1=2003$ was also included.

As stated above, the role of ICT as enabling technologies, jointly with the assumption that ICT consulting is aimed at improving the general environment inside the firm, implies that some unobserved factors inside the innovative process might be correlated with the decision to contract ICT consulting. For this reason, the analysis follows an ordinary least squares, as well as an instrumental variables approach to account for the potential endogeneity present in the ICT consulting decision. In particular, the empirical strategy controls for the potential endogeneity of the decision to contract ICT consulting in two different ways. First, when possible, the analysis includes lagged explanatory variables whose effects are, hopefully, internalize by the time the dependent variable $y_{i, t}$ is sampled. Second, the binary variable corresponding to the ICT consulting decision is instrumented with a binary $(0,1)$ variable that states whether the

\footnotetext{
${ }^{19}$ See Wooldridge $(2008)$ for a procedure to estimate the function $h(x, z ; \widehat{\theta})$.

${ }^{20} \mathrm{ICT}$ consulting is instrumented using its propensity score that includes the available instruments. See Wooldridge (2002, 2008).

${ }^{21}$ The consideration of alternative innovative output and/or input variables corresponds to current research.
} 
firm in question contracted ICT-related consulting in the year 2000 to evaluate the potential costs associated with the Y2K Millenium-Bug.

This instrument is expected to be (and it actually is) significantly correlated with the decision to contract ICT consulting in the year 2003. In particular, both variables tend to exhibit a value of 1 for firms that are ICT intensive and were more exposed to the Millenium-Bug and, potentially, to updating needs in their ICT infrastructure. However, the impact of the Y2K consulting decision on innovation incentives and/or productivity should be fully internalized by the year 2003 when the ICT consulting decision was made. An additional variable describing the presence of a work council in the firm was also considered as an instrument. In particular, work councils allow for a more direct participation of the employees in the relevant decisions of the German companies. Work councils might influence organizational decisions inside the firm as the contracting of ICT consulting, specially if employees consider a consultant as a threat (e.g. supporting outsourcing strategies). However, the decision of establishing a work council go back in time and is completely independent of the ICT consulting decision taken in 2003. Table 3 presents some descriptive information, taking in two account the instrumental variables. Endogeneity tests (e.g. Hausman test) were also successfully performed in order to check the validity of the instrumental variables approach.

\section{Results}

Table 4 presents the results of the average treatment effect of the contracting of ICT consulting in 2003 on the percentage of sales reported in 2006 that are derived from the product innovations introduced during the period 2004-2006 as a measure of innovative output. Column 1 reports the results from the benchmark OLS estimations. As can be seen, ICT consulting does not appear to have any impact of the innovative activity reported by the sampled firms. However, due to the many different consequences that consulting can have on firms' performance, it is reasonable to suspect the presence of endogeneity in the estimation approach.

In order to consider the potential endogeneity, column 2 instruments ICT consulting with the existence of consulting activities related with the Y2K phenomenon in the year 2000 (i.e. first stage). In contrast with the theoretical model, column 2 shows that low productivity firms do not exhibit a higher tendency to contract ICT consulting ${ }^{22}$ Column 3 consider the case of homogeneous treatment (i.e. specification presented in equation (19p), using the propensity

\footnotetext{
${ }^{22}$ Note that the propensity score estimated in column 2 and used as instrument does not correspond to a complete analysis of the incentives to contract ICT consulting. In fact, as highlighted in Wooldridge (2002, 2008) the propensity score is not required to be consistently estimated in order to provided a valid instrument. Therefore, the results of column 2 are inconclusive.
} 
score as instrument. That is, it is assumed that all firms are affected equally by the contracting of ICT consulting. In this case, ICT consulting seems to affect the value of introduced product innovations negatively (coeff.: -0.26, std. error: 0.09). This result states that, on average, contracting ICT consulting reduces the value of the introduced product innovation by $26 \%$. For example, for the average value of the introduced innovation, this result is equivalent to a reduction from 137 to 96 thousand euros.

In addition, the results suggest that ICT still promotes the innovative capabilities at the firm level. As the results from column 3 show, PCW and CRM affect positively the value of introduced product innovations (coeff: 0.13 , std. error: 0.03, and coeff: 0.03, std. error: 0.02, respectively). Note that CRM is an ICT application oriented at improving the communication of the firm with final consumers and, thus, this result is in line with the expected impact of such applications. Moreover, not surprisingly, the variable indicating that the firm introduced product innovation during the period 2001-2003 is also positive and significant (coeff: 0.11, std. error: 0.02), suggesting the positive impact of experience in innovative efforts.

One of the potential hypothesis that can explain the negative (average) impact of ICT consulting suggests that, through consulting, firms optimize their innovation portfolio. By applying the knowledge acquired from the contracting of ICT consulting, firms are able to concentrate on their core competencies, reducing the risk associated with innovative activities. This hypothesis is supported by the additional result (not reported) that ICT consulting does not increase neither the probability of introducing product innovation or the number of such innovations.

The previous result was obtained under the assumption that ICT consulting affects firms equally. Column 4 departs from this assumption and considers the case of heterogeneous treatment (i.e. specification presented in equation (20p). Under this specification, the analysis attempts at recovering the impact of ICT consulting on the value of introduced innovations under the assumption that firms benefit differently from such consulting but still recovering the value of the average treatment effect. The main result is robust to this consideration. That is, ICT consulting affects the value of introduced product innovations negatively (coeff.: -0.25 , std. error: 0.14). Under this specification, surprisingly, PCW and CRM do not affect innovative activities, while SCM does (coeff: -0.18 , std. error: 0.10). Note that the marginal effect of SCM is close to zero, once the specification for the heterogeneous treatment effect is considered. Under this specification presented in column 4, ERP appears to increase the value of the introduced product innovations by $18 \%$ for firms that contracted ICT consulting.

Columns 5 and 6 consider the case of homogeneous and heterogeneous treatment effects in the presence of correlated random coefficients (i.e. specifications presented in equations (21) and 
(22)). As the result of column 4 shows, ICT consulting affects the value of introduced product innovations negatively (coeff.: -0.26 , std. error: 0.09 ) indicating the robustness of the previous results and the irrelevance of considering a correlated random coefficient specification.

In sum, ICT consulting appears to negatively affect the value of introduced product innovations, even though the adoption of ICT appears to clearly support innovative activities. This result suggests that ICT consulting helps the firms to optimize their innovation portfolio, by allowing those firms to concentrate on less risky innovative efforts. As will be further discussed below, this hypothesis is consistent with the findings that ICT consulting does not increase neither the probability of introducing product innovation nor the number of such innovations, while at the same time increases firm productivity and outsourcing activities that may compensate a less risky innovative strategy.

Table 4 only considered the impact of ICT consulting on the value of introduced product innovations. However, the data also allows the analysis to include the impact of ICT consulting on the value of introduced process innovations. Table 5 provides the results of such analysis. In particular, the dependent variable in Table 5 corresponds to the percentage of cost reductions achieved in 2006 from the introduction of process innovations during the period 2004-2006. The empirical strategy is the same as the one presented in column 4 . That is, the average treatment effect was estimated, considering the role of firm unobserved heterogeneity from equations (19)(22).

As before, column 1 of Table 5 presents the results of the benchmark OLS estimations. Given the suspected presence of endogeneity, the results are the same as those presented in Table 4. Under OLS, ICT consulting does not appear to have any impact on the value of process innovations introduced. Column 3 extends the analysis and considers the estimation of the (homogeneous) average treatment effect with an instrumental variables strategy. As before, the instrument employed corresponds to the presence of consulting activities related with the Y2K phenomenon in the year 2000.

Consistent with the results reported in Table 4, column 3 of Table 5 shows that ICT consulting affects the value of the introduced process innovations negatively (coeff.: -0.06 , std. error: 0.03). Interestingly, the adoption of ICT positively affects the value of such innovations. In particular, PCW (coeff: 0.03, std. error: 0.00), ERP (coeff: 0.03, std. error: 0.00), SCM (coeff: 0.01, std. error: 0.00) exhibit a positive effect on the value of such innovations. Note that in this case (i.e. value of process innovations) only ICT variables related with the production process, as opposed to the relationship with clients (e.g. CRM), evidence a positive impact. In addition, the introduction of process innovations during the period 2001-2003 is also positive and significant (coeff: 0.02, std. error: 0.00), suggesting, again, the positive impact of experience in 
innovative efforts.

Under the hypothesis that ICT consulting helps firms to optimize their internal structure, this result is not surprising. Moreover, a dummy variable indicating firms whose productivity level in 2003 was within the 50th percentile of its distribution is also positive and significant (coeff: 0.01 , std. error: 0.00 ). This finding points to higher innovative efforts by low productivity firms, as a strategy to improve their competitiveness. This result is consistent with the insights from the theoretical model when $y_{1}^{*}<y_{2}^{*}$ under a particular parameter configuration. Additional results of column 3 show that firms which reported exporting activities in 2003 and firms in the service sector, evidenced a lower value of process innovations introduced during 2004-2006.

Column 4 presents the results under heterogeneous treatment and, not surprisingly, shows that ICT consulting affected the value of process innovation negatively (coeff: -0.09 , std. error: 0.05). Note that under heterogeneous treatment (i.e. accounting unobserved firm heterogeneity in the impact of ICT consulting), the impact increases by $50 \%$, from -0.06 to -0.09 , although the interaction terms showed no significance. This result suggest that for the case of process innovations, unobserved heterogeneity is an important factor not accounted by the available data. Columns 5 and 6 report the analysis under correlated random coefficients without any evidence of it. In sum, Table 5 corroborates the results presented in Table 4, showing some interesting differences in the impact of ICT consulting on process innovations in comparison to product innovations.

\section{Conclusions}

This paper studies the economic impact of the decision to contract ICT consulting. In spite of the fast technological progress in the ICT producing sector and the apparent recent economic importance of ICT consulting, this paper represents a first attempt to quantify its economic benefits. In particular, the paper develops a theoretical model that explains the effect of this decision on firms' innovative incentives and estimates some of its predictions for a sample of German firms. The analysis provides three main results. First, the results of the theoretical model show that ICT consulting increases aggregate incentives to innovate. This result is not corroborated by the empirical application. In particular, ICT consulting does not exhibit any impact on the probability of introducing product or process innovations nor on the number of such innovations. Interestingly, the results show that ICT consulting actually affects negatively the value of the introduced product and processes innovation. Second, the theoretical model suggests that low productivity firms might evidence either lower, unaffected or higher incentives to innovate. The empirical application shows that low productivity firms exhibit higher incen- 
tives to innovate. Third, although the theoretical analysis shows that the lower the productivity level the more the incentives to contract ICT consulting, the empirical evidence is inconclusive on this matter. These results suggest that firms optimize their innovations portfolio through ICT consulting. 


\section{References}

Banerjee, S. and P. Lin, 2003, Downstream R\&D, Raising Rivals' Costs, and Input Price Contracts. International Journal of Industrial Organization, 21, 79-96.

BDU, 2008, Facts \& Figures zum Beratermarkt 2007. Studie des Bundesverbands Deutscher Unternehmensberater e. V. Bonn.

Bresnahan, T. and M. Trajtenberg, 1995, General Purpose Technologies: 'Engines of growth'. Journal of Econometrics, 65, 83-108.

Brocas, I., 2003, Vertical Integration and Incentives to Innovate. International Journal of Industrial Organization, 21, 457-88.

Brynjolfsson, E. and L. Hitt, 2000, Beyond Computation: Information Technology, Organizational Transformation and Business Performance. Journal of Economic Perspectives, 14 (4), 23-48.

Buehler, S. and A. Schmutzler, 2008, Intimidating Competitors - Endogenous Vertical Integration and Downstream Investment in Successive Oligopoly. International Journal of Industrial Organization, 26, 247-65.

Cerquera, D. and G. J. Klein, 2008, Endogenous Firm Heterogeneity, ICT and R\&D Incentives, ZEW Discussion Paper No. 08-126, Mannheim.

Draca, M., R. Sadun and J. Van Reenen, 2007, Productivity and ICT: A Review of the Evidence, In Mansell, R., C. Avgerou, D. Quah and R. Silverstone (Eds.), The Oxford Handbook of Information and Communication Technologies, Oxford.

Hart, O., 1995, Firms, Contracts and Financial Structure. Oxford, U.K. Oxford University Press.

Hart, O. and J. Moore, 1990, Property Rights and the Nature of the Firm, Journal of Political Economy 98 (6), 1119-58.

Helpman, E., 1998, General Purpose Technologies and Economic Growth. MIT Press.

Helpman, E. and M. Trajtenberg, 1998, Diffusion of General Purpose Technologies. In E. Helpman (ed.), General Purpose Technologies and Economic Growth. MIT Press.

Jorgenson, D., M. Ho and K. Stiroh, 2008, A Retrospective Look at the U.S Productivity Growth Resurgence, Journal of Economic Perspectives, 22, 1, 3-24.

Jovanovic, B. and P. L. Rousseau, 2005, General Purpose Technologies, in: P. Aghion and S. Durlauf (Eds.), Handbook of Economic Growth, Edition 1, Vol.1, 1181-224. 
OECD, 2003, ICT and Economic Growth - Evidence from OECD Countries. OECD Paris.

Reinganum, J., 1989, "The Timing of Innovation: Research, development and diffusion". In R. Schmalensee and R. Willig, (Eds.) (1989). Handbook of Industrial Organization, NorthHolland. 849-908.

Singh, N. and X. Vives, 1984, Price and Quantity Competition in a Differentiated Duopoly, RAND Journal of Economics, 15(4), 546-54.

Milstein, I. and A. Tishler, 2008, R\&D Wars and the Effects of Innovation on the Success and Survivability of Firms in Oligopoly Markets, International Journal of Industrial Organization, forthcoming.

Wooldridge, J., 2002, Econometric Analysis of Cross Section and Panel Data. MIT Press.

Wooldridge, J., 2008, Instrumental Variables Estimation of the Average Treatment Effect in the Correlated Random Coefficient Model, Advances in Econometrics, Elsevier, Vol. 21, 93-116. 


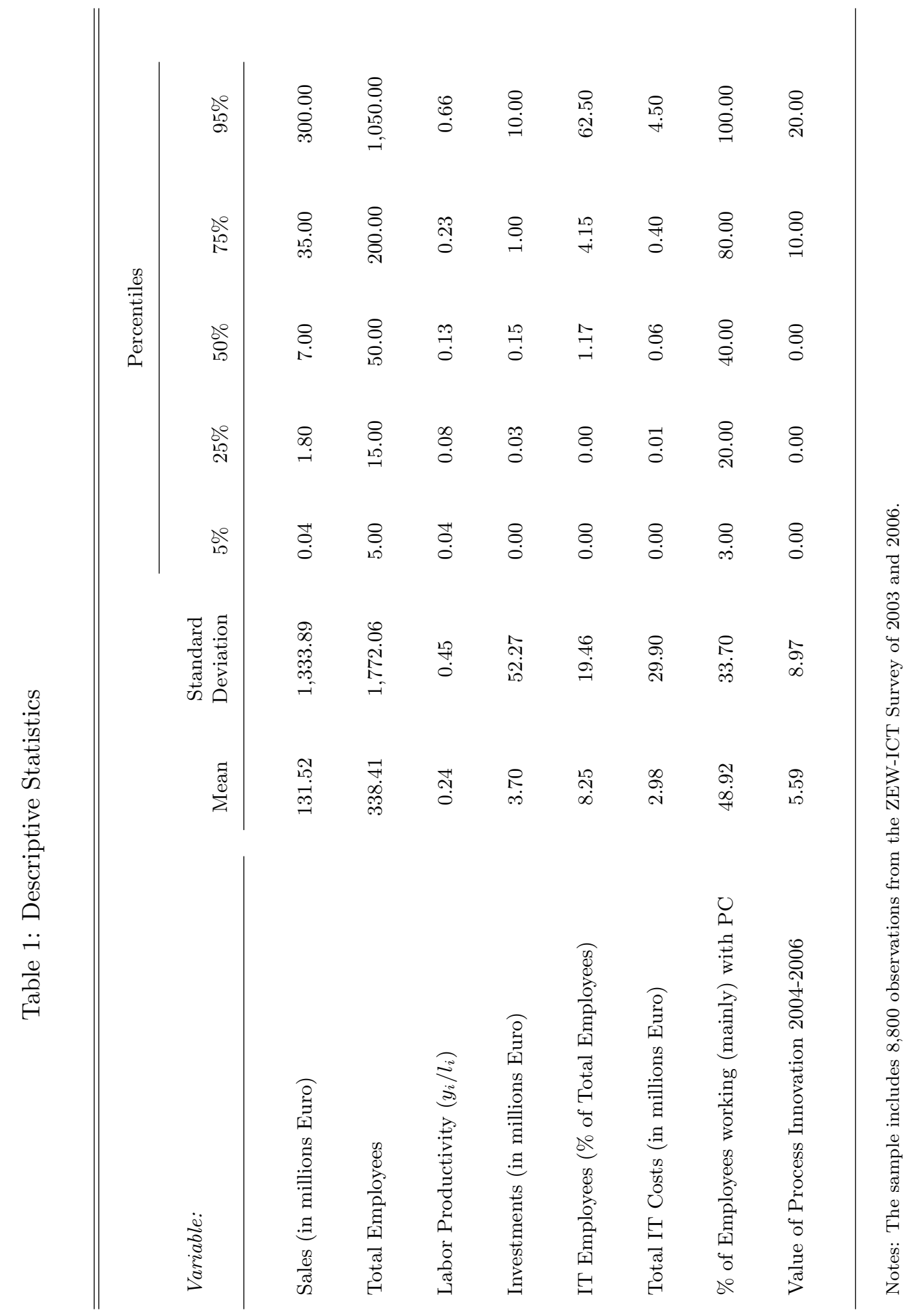




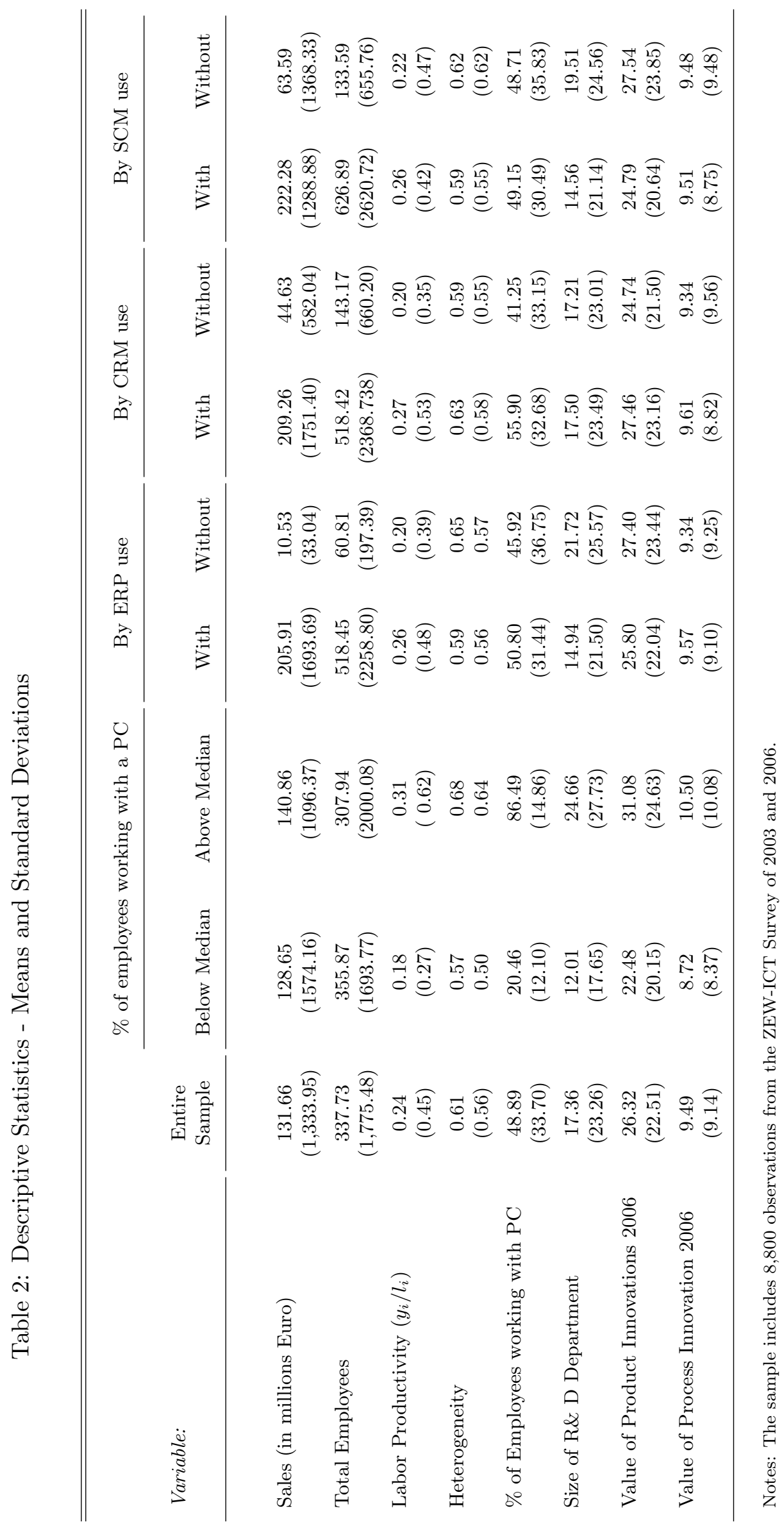




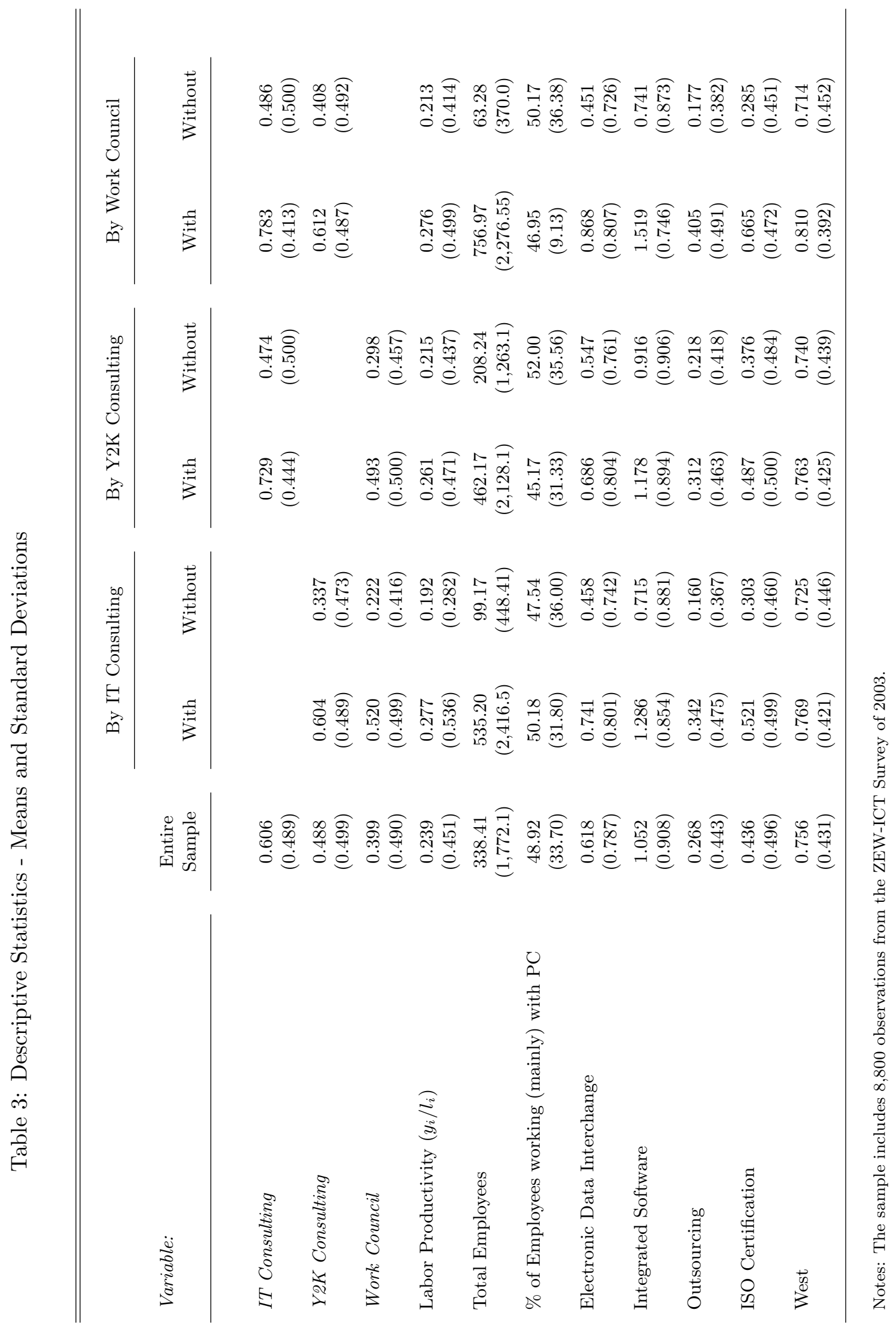




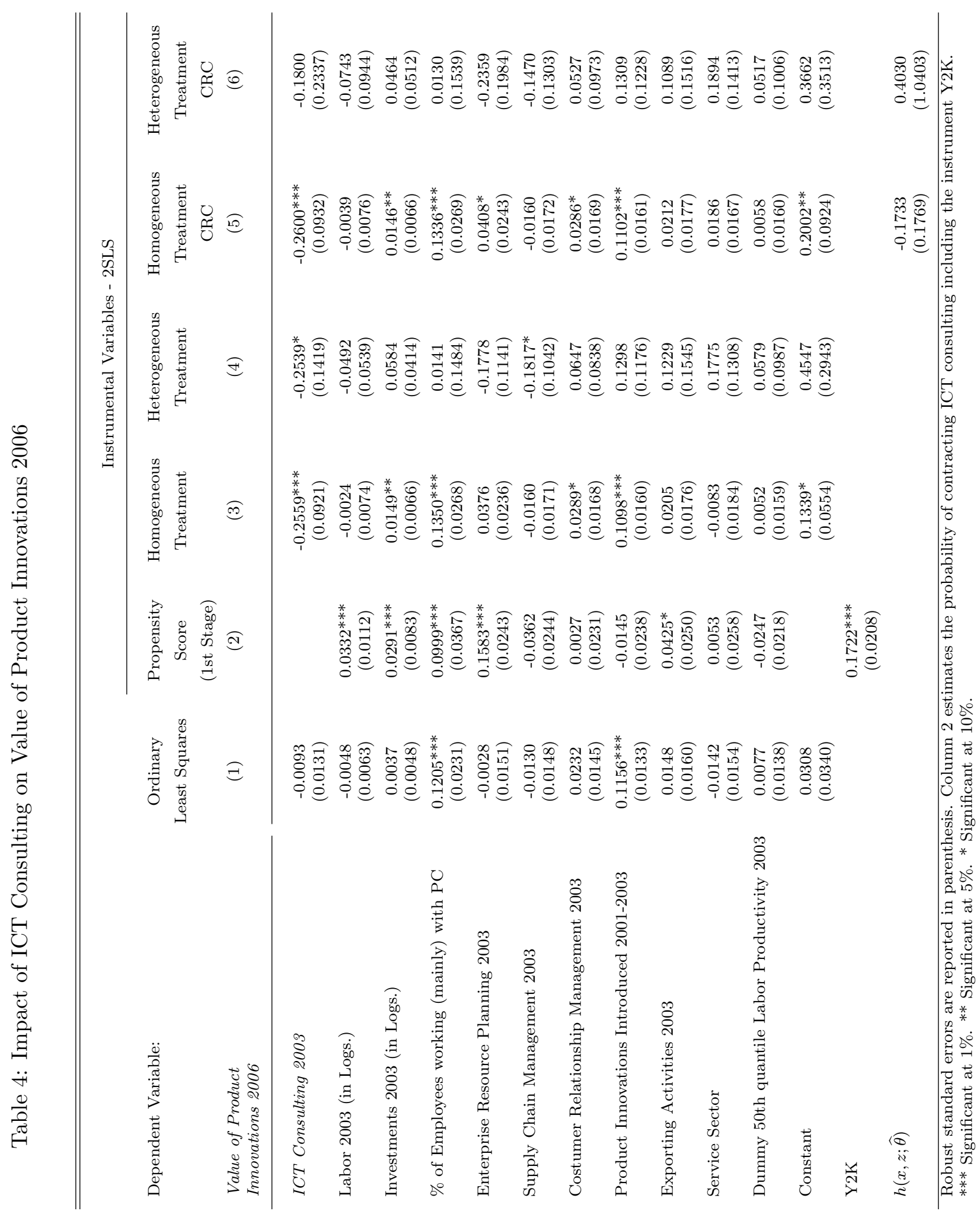




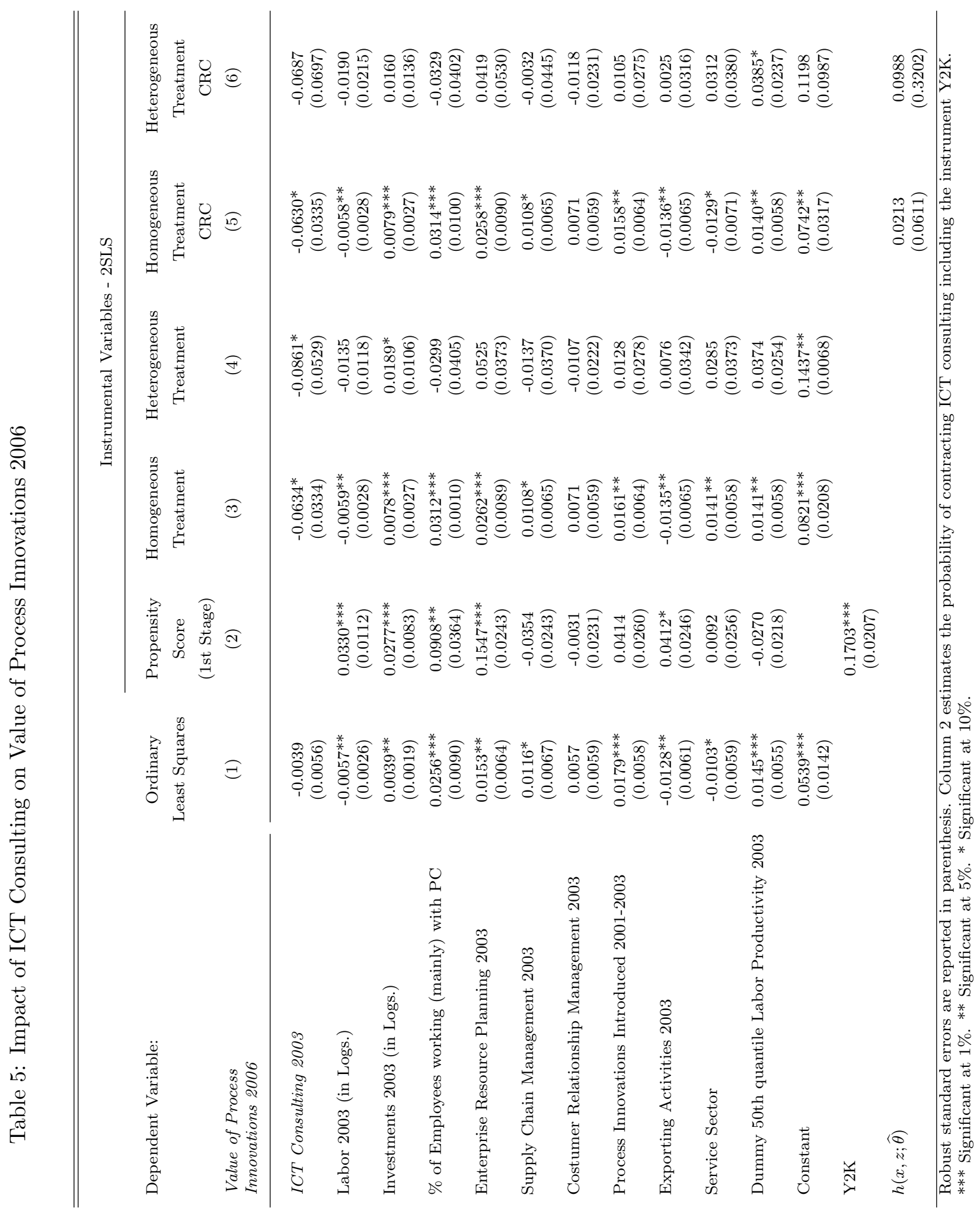

